\title{
Fine Needle Aspiration Cytology of Granulomatous Lesions of The Breast : A Six-Year Retrospective Study
}

\author{
Bhavna Nayal ${ }^{1}$, Geetha Vasudevan ${ }^{1}$ and Varun Kumar Singh ${ }^{2 *}$ \\ 'Pathology, Kasturba Medical College, Manipal, Manipal Academy of Higher Education, India \\ ${ }^{2}$ Pathology, Melaka Manipal Medical College, Manipal campus, Manipal Academy of Higher Education, India
}

\section{ABSTRACT}

Background: Granulomatous lesions of the breast are uncommon and can mimic malignancy. Fine needle aspiration (FNA) is among the first investigations in such patients. Cytological diagnosis in the absence of granulomas may pose a diagnostic dilemma. The present study outlines the cytological features of such lesions.

Methods: This was a 6-year (January 2011 and December 2016) retrospective study. Cases with a biopsy proven diagnoses of granulomatous mastitis having FNA of the corresponding lesion were included in the study. Clinical, radiological and microbiological details were retrieved from the medical records. The cytology slides were reviewed and correlated with clinical and histopathological findings.

Result: Thirty-two cases were included in the study. The age range was 22 to 62 years. On cytology, 17 showed well-formed granulomas. One case each of Mycobacterium tuberculosis and Burkholderia pseudomallei were identified by culture. Among the 15 cases with no granulomas, scattered histiocytes and giant cells were seen. Most patients presented with breast lump and fever. Uncommon presentations included peau de orange, skin erythema, induration, nipple retraction and axillary lymphadenopathy. Most lesions were hypoechoic on mammography. Nine cases were clinically suspicious for malignancy while rest were diagnosed as abscess, fibroadenoma or mastitis.

Conclusion: In the developing world, tuberculosis and meliodosis can present with granuloma formation. In the breast, these entities can have overlapping features with idiopathic granulomatous mastitis. In the absence of granulomas on cytology, these lesions may be mislabeled as breast abscess. In such cases, the presence of scattered histiocytes and giant cells may aid in diagnosing these lesions.

\section{Keywords: Granulomatous Mastitis, Mycobacterium Tuberculosis, Meliodosis, Histiocytes, Giant Cells}

\section{Introduction}

Granulomatous lesions of the breast are uncommon. Among the various causes, tuberculosis is the most common one. These patients often present with breast lump mimicking malignancy clinically and radiologically. Histopathological examination of the lesion and microbiology are required for definitive diagnosis. ${ }^{(1,2)}$

Fine needle aspiration cytology is a simple, less invasive and cost effective initial investigation in patients presenting with breast lump. The presence of granulomas prompts the diagnosis of granulomatous mastitis. However, cytological diagnosis in the absence of well-formed granulomas may pose a diagnostic dilemma. ${ }^{(3)}$ The present study was carried out to study the cytological features of such lesions.

\section{Materials and Methods}

A 6-year retrospective study was conducted on all patients with a histopathological diagnosis of granulomatous mastitis between January 2011 and December 2016 in a tertiary care hospital. Patients having fine needle aspiration cytology of the corresponding lesion were included in the study. The clinical details, radiological and microbiological investigations were retrieved from the medical records.
The Papanicolaou stained cytology slides were reviewed. The morphological features analyzed were presence of granulomas, epithelioid histiocytes, giant cells, background inflammatory cells, necrosis and epithelial fragments. These findings were correlated with the respective clinical and histopathological findings.

\section{Result}

One hundred and twenty cases of granulomatous mastitis were diagnosed in the 6-year study period. Of these, only 32 women had undergone fine needle aspiration. All the patients were females in the age range of 22 to 65 years with the mean age of 33.8 years. Twenty-six patients were in the age group of 22 to 45 years.

Clinical details of 28 of the 32 cases were available. The common presenting was breast lump. The lump was associated with pain and fever in 12 and 4 cases respectively. Three cases had post-partum period of less than 5 years. On examination, the size of the lump varied from $1.5 \times 1.5 \mathrm{~cm}$ to $10 \times 10 \mathrm{~cm}$. The overlying skin showed peau- de- orange appearance in 2 and erythema in one case. Two cases had nipple retraction and one had induration of the overlying skin. Seven had associated axillary lymph 
node enlargement. The duration of symptoms ranged from 5 days to 2 years. There were no other systemic complaints or signs in these patients. Mammography findings were available for 20 cases; 9 showed well defined and 11 illdefined lesions. Clinical diagnosis included malignancy, fibroadenoma, abscess and mastitis in 9,1, 7 and 11 cases respectively. Microbiological investigations identified one case each of Mycobacterium tuberculosis and Burkholderia pseudomallei (meliodosis) by culture of the breast tissue or discharge. No growth was seen in the culture in other cases. Polymerase chain reaction for Mycobacterium tuberculosis was performed in 2 cases and was reported negative.

On reviewing the Papanicolaou stained slides of fine needle aspiration in all 32 cases, 17 showed well- formed granulomas.

Other findings included presence of singly dispersed histiocytes, foreign body type giant cells, numerous neutrophils, cell debris and necrosis. No caseous necrosis was identified. The cytomorphological features are described in table no 1.

The biopsies of all 32 cases of granulomatous mastitis stained negative for acid fast bacilli on Zeel- Neelson stain and fungus on Periodic Schiff stain.

Hence, based on microbiology, one case each of tuberculous mastitis and breast meliodosis was diagnosed. No infectious cause could be ascertained in the remaining 15 cases.

Therapy given included excision in 17 cases, incision and drainage in 8 and medical management in 4 cases. Of the latter, three were treated with antibiotics and the one with steroids. Rest of the patients were also given additional antibiotics. Patient with test positive for Mycobacterium tuberculosis was treated with incision and drainage along with anti-tuberculosis therapy.

Table 1: Cytomorphological features of granulomatous mastitis $(n=32)$.

\begin{tabular}{|c|c|c|c|c|}
\hline \multirow[t]{2}{*}{ Morphological finding } & \multicolumn{2}{|l|}{ Granuloma (n=17) } & \multirow{2}{*}{$\begin{array}{l}\text { Absent granuloma }(n=15) \\
\text { Unknown etiology }\end{array}$} & \multirow[t]{2}{*}{ Total $(n=32)$} \\
\hline & Unknown etiology $(n=7)$ & Infections* $(n=2)$ & & \\
\hline Scattered histiocytes & 11 & 2 & 11 & $24(75 \%)$ \\
\hline Giant cells & 14 & 2 & 11 & $27(84 \%)$ \\
\hline $\begin{array}{l}\text { Scattered histiocytes + } \\
\text { Giant cells }\end{array}$ & 10 & 2 & 5 & $17(53 \%)$ \\
\hline Necrosis & 6 & 2 & 11 & $19(59 \%)$ \\
\hline Epithelial cells & 10 & 0 & 11 & $21(66 \%)$ \\
\hline Stromal fragments & 3 & 1 & 2 & $6(19 \%)$ \\
\hline
\end{tabular}

*included the cases diagnosed as tuberculosis and meliodosis

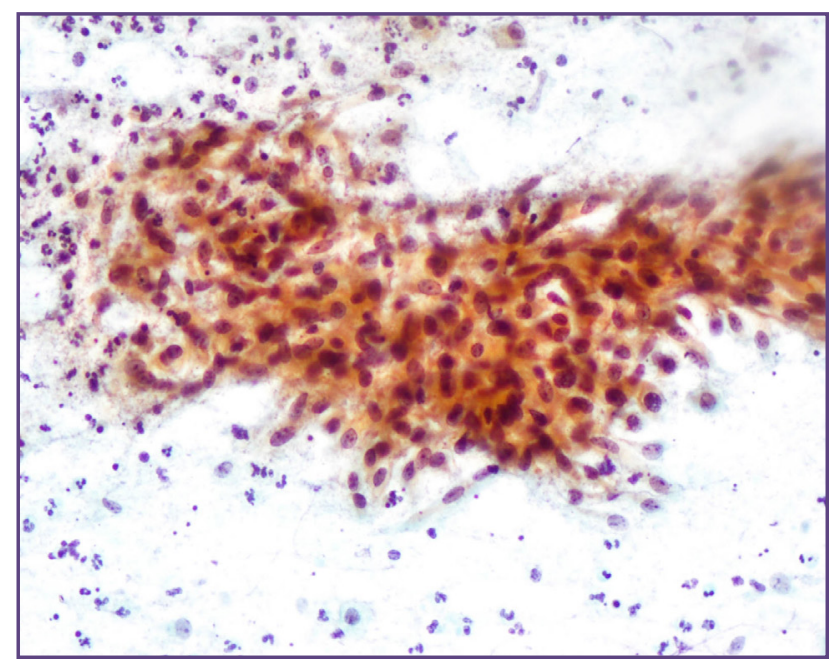

Fig. 1: Well formed granuloma composed of epithelioid histiocytes and lymphocytes (PAP, X20).

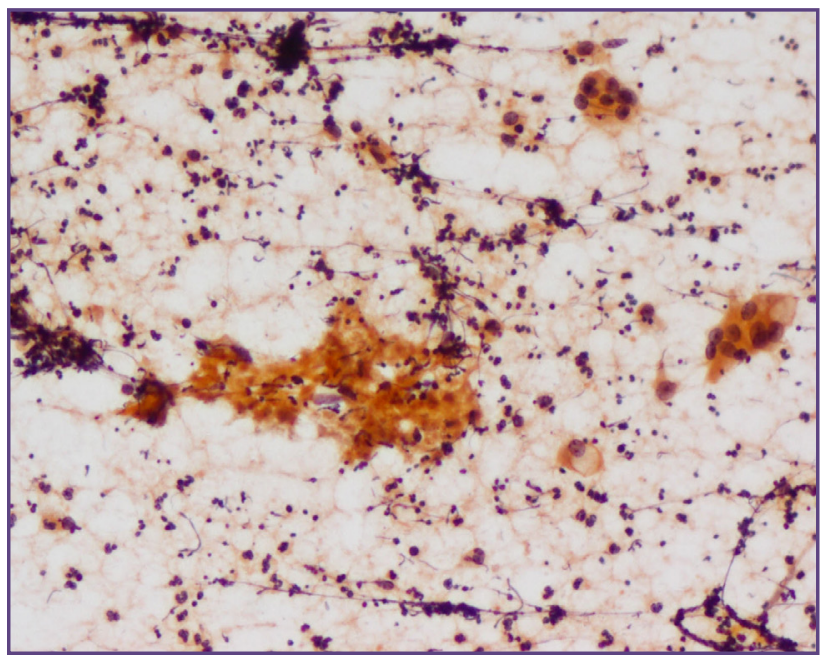

Fig. 2: Necrosis with foreign body giant cells (PAP, X10). 




Fig. 3: Inflammatory cells with scattered epithelioid histiocytes (PAP, X20).



Fig. 4: Epitheilial fragment surrounded by inflammatory cells (PAP, X20).

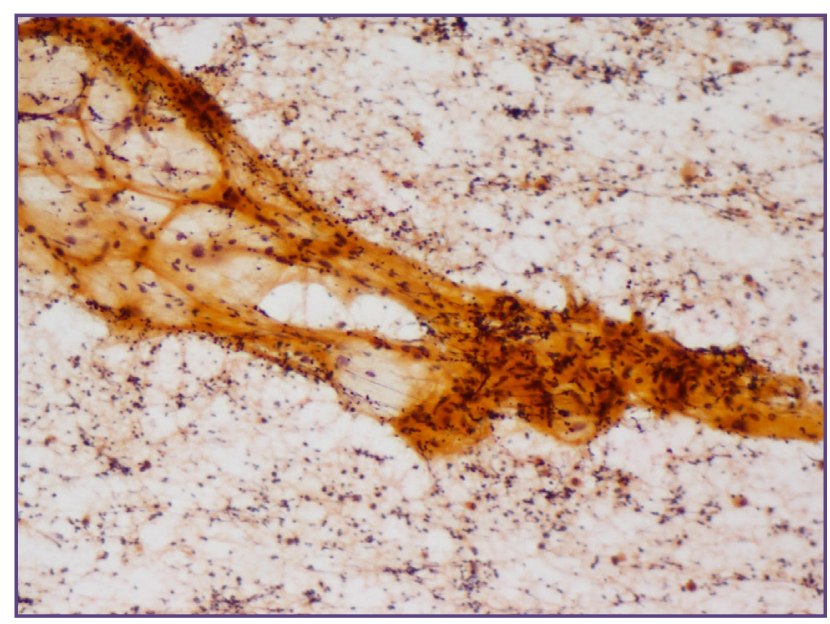

Fig. 5: Stromal fragment surrounded by inflammatory cells (PAP, X10).

\section{Discussion}

Granulomatous lesions in the breast are rare and may be due to infections, Wegners granulomatosis, foreign body reaction, fat necrosis and sarcoidosis. In india, the most common cause is tuberculosis. Other infections include Burkholderia, fungi and filarial. Gram positive bacilli has also been proposed as an etiological factor. After excluding all the other causes of granulomatous inflammation, the diagnosis of idiopathic granulomatous mastitis (IGM) is suggested. ${ }^{(1,2,4)}$ Proposed etiological factors of IGM include use of oral contraceptive pills, autoimmune disorders, alpha one antitrypsin deficiency, hyperprolactinemia, smoking, diabetes mellitus and viral infection. It usually affects females in reproductive age group. There is an association with pregnancy and lactation. It has been proposed that the inciting agent causes ductal epithelial damage resulting in extravasation of glandular secretions and inflammatory reaction. ${ }^{(1,5,6)}$

The common presentation in patients with breast disease is breast lump. In IGM, the lump is often painful. Associated changes include nipple retraction, peaude orange appearance of skin, erythema and regional lymphadenopathy. Radiological findings are nonspecific, and these lesions often present as ill-defined hypoechoiec masses mimicking a neoplastic process. $(2,6,7)$ Tuberculous mastitis also presents as breast lump while meliodosis usually presents as abscess. $(8,9)$ All the patients in the present study presented with breast lump. Nine cases were suspected to be malignant in this series.

Fine needle aspiration is an essential first line of diagnostic procedure in breast lumps. They characteristically show epithelioid cells with abundant eosinophilic cytoplasm and reniform nuclei. These cells may be present singly or in aggregates forming granulomas. Presence of isolated epithelioid cells also indicates the possibility of granulomatous lesion in the absence of well-formed granulomas. These epithelioid cells may show atypia and may be confused for neoplastic epithelial cell of mammary origin. Other findings including the presence of multinucleated giant cells, neutrophils, lymphocytes and plasma cells help in identifying the reactive nature of the lesion. Necrosis (non caseating) and epithelial cell fragments may also be present $(10,11,12,13,14)$ Studies by Gangopadhyay et al and Helal et al have reported a predominance of neutrophils in their studies. $(4,13)$ According to Helal et al, presence of neutrophils and absence of foamy histiocytes can help in ruling out tuberculosis, fat necrosis and duct ectasia. (4) In the current study, Background showed a population of mixed inflammatory cells composed of neutrophils, lymphocytes and plasma 
cells in all cases, including tuberculosis. However, singly scattered epithelioid cells and necrosis was seen in $75 \%$ and $59 \%$ of the cases, respectively. Giant cells were present in 11 of the 15 cases without granulomas, giving a clue to the granulomatous nature of the lesion.

Infectious cause of granulomatous inflammation can be confirmed by biopsy and culture. Tuberculous mastitis usually shows granulomas with caseous necrosis. Diagnosis is confirmed by biopsy, demonstration of acid fast bacilli by staining or culture and polymerase chain reaction. $(8,9)$ Granulomas along with non-caseating necrosis was present in both the infective cases in our group.

On cytology, a diagnosis of 'granulomatous lesion' of breast should be suggested on identifying epithelioid cells and multinucleate giant cells. This term includes a wide spectrum of lesions including infectious etiology and idiopathic granulomatous mastitis (11) The final diagnosis of granulomatous lesion is based on both histopathology and findings on culture.

\section{Conclusion}

In the developing world, infections like tuberculosis and meliodosis can present as granulomatous lesions of the breast. Fine needle aspiration being used in almost all clinical setting, provides an essential tool to detect these lesions. Cytomorphological features in these cases can have overlapping features with idiopathic granulomatous mastitis. In the absence of well-formed granulomas on cytology, these lesions may be missed. In such a scenario, the presence of scattered histiocytes and giant cells may aid in identifying these lesions. However, extensive histological sampling and microbiological investigations are crucial to exclude other etiological causes before diagnosing IGM.

\section{Reference}

1. Hatwal D, Panda A, Suri V. Idiopathic Granulomatous Mastitis - Report of A Case

2. With A Brief Review Of Literature. J Clin Diagn Res. 2010;4:2913-7.

3. Bakaris S, Yuksel M, Ciragil P, Guven MA, Ezberci F, Bulbuloglu E. Granulomatous mastitis including breast tuberculosis and idiopathic granulomatous mastitis. Can J Surg. 2006 Dec;49(6):427-30.

4. Gangopadhyay M, De A, Chakrabarti I, Ray S, Giri A, Das $\mathrm{R}$. Idiopathic granulomatous mastitis-utility of fine needle aspiration cytology (FNAC) in preventing unnecessary surgery. J Turk Ger Gynecol Assoc 2010;11(3):127-30.

5. Helal TE, Shash LS, Saad El-Din SA, Saber SM. Idiopathic granulomatous mastitis: cytologic and histologic study of 65 Egyptian patients. Acta Cytol. 2016;60(5):438-44.

6. Boufettal H, Essodegui F, Noun M, Hermas S, Samouh N. Idiopathic granulomatous mastitis: a report of twenty cases. Diagn Interv Imaging. 2012 Jul;93(7-8):586-96.

7. Kiyak G, Dumlu EG, Kilinc I, Tokaç M, Akbaba S, Gurer A, Ozkardes AB, Kilic M. Management of idiopathic granulomatous mastitis: dilemmas in diagnosis and treatment. BMC Surg. 2014 Sep 4;14:66.

8. Vidyavathi K, Udayakumar M, Suresh TN, Sreeramulu PN. Granulomatous Mastitis: A Cytological Dilemma. J Cytol Histol 2012; 3:137.

9. Tauro LF, Martis JS, George C, Kamath A, Lobo G, Hegde BR. Tuberculous mastitis presenting as breast abscess. Oman Med J. 2011 Jan;26(1):53-5.

10. Mickail N, Klein NC, Cunha BA, Schoch PA. Melioidosis breast abscesses. J Infect 2102;64(4):434-5.

11. Gupta RK. Fine needle aspiration cytology of granulomatous mastitis: a study of 18 cases. Acta Cytol. 2010 MarApr;54(2):138-41.

12. Kishore B, Khare P, Gupta RJ, Bisht SP. Fine Needle Aspiration Cytology in the Diagnosis of Inflammatory Lesions of the Breast with emphasis on Tuberculous Mastitis. J Cytol 2007;24(3):155-6.

13. Tse GMK, Poon CSP, Law BKB, Pang LM, Chu WCW, Ma TKF. Fine needle aspiration cytology of granulomatous mastitis. J Clin Pathol 2003;56:519-21.

14. Gangopadhyay M, De A, Chakrabarti I, Ray S, Giri A, Das R. Idiopathic granulomatous mastitis-utility of fine needle aspiration cytology (FNAC) in preventing unnecessary surgery. J Turk Ger Gynecol Assoc 2010;11(3):127-30.

15. Ail DA, Bhayekar P, Joshi A, Pandya N, Nasare A, Lengare P, Narkhede KA. Clinical and cytological spectrum of granulomatous mastitis and utility of FNAC in Picking up tubercular mastitis: an eight-year study. J Clin Diagn Res. 2017 Mar;11(3):EC45-EC49.

*Corresponding author:

Dr. Varun Kumar Singh: Cabin 305, Melaka Manipal Medical College, Manipal campus, Madhav Nagar, Manipal, Karnataka - 576104, India

Phone: +91 9506423336

Email: varunksingh2k5@gmail.com

Financial or other Competing Interests: None. 